\title{
Chromosome 22q Allelic Losses at Microsatellite Loci in Human Astrocytic Tumors
}

\author{
A. K. M. Ghulam Muhammad, Toshiki Yoshimine, Motohiko Maruno, \\ Koji TOKIYOSHI, Osamu TAKEMOTO, and Toru HAYAKAWA
}

Department of Neurosurgery, Osaka University Medical School, Suita, Osaka

\begin{abstract}
Common regions of deletion(s) on chromosome $22 q$ and the correlations between loss of heterozygosity and patient survival were analyzed in 19 deoxyribonucleic acid samples from astrocytic tumors (3 astrocytomas, 5 anaplastic astrocytomas, and 11 glioblastomas) and matched normal brain tissues. The polymerase chain reaction products using five microsatellite markers were electrophoresed on polyacrylamide gels and the ethidium bromide stained bands were photographed. Loss of heterozygosity was observed in $14(74 \%)$ of 19 samples, with similar incidences in astrocytomas, anaplastic astrocytomas, and glioblastomas $(67 \%, 60 \%$, and $82 \%$, respectively). The locus D22S300 (q12.1-q13.1) was most frequently involved, with loss of heterozygosity in eight (80\%) of 10 informative glioblastomas at this locus. Increased loss of heterozygosity during tumor progression or recurrence was seen in two patients at the D22S300 (q12.1-q13.1) and TOP1P2 (q11.2-q13.1) loci. No correlation between loss of heterozygosity on chromosome 22 and the postoperative survival was found. These findings suggest that loss of heterozygosity on chromosome 22q probably occurs quite frequently in astrocytic tumors. The chromosome segment 22q12.1-q13.1, around the D22S300 locus, may be the common region of deletion in glioblastomas.
\end{abstract}

Key words: chromosome 22q, microsatellite loci, loss of alleles, patient survival, astrocytic tumors

\section{Introduction}

Chromosomal aberrations of various types are a distinctive feature of human tumors. Aberrations in chromosome 22 are associated with many congenital and acquired pathologies including neurofibromatosis type 2 (NF2) and meningioma. ${ }^{1,12)}$ Such aberrations also occur in $10-30 \%$ of astrocytic tumors, ${ }^{9,18,20)}$ and in $44 \%$ of these tumors in female patients. ${ }^{6)}$ However, the precise loci of the deletions and their clinical relevance are yet to be defined.

The present loss of heterozygosity analysis was performed using highly polymorphic microsatellite markers. Astrocytic tumors of various histological subtypes were studied to identify the common region(s) of deletion and to evaluate the clinical significance of these aberrations in terms of patient survival.

Received December 27, 1996; Accepted May 19, 1997

\section{Materials and Methods}

Tissue samples were obtained at open surgery from three cases of astrocytoma, five anaplastic astrocytomas, and 11 glioblastomas (World Health Organization classification). ${ }^{11}$ Eleven were primary lesions removed prior to chemoradiotherapy. The samples were embedded in TISSUE TEK OCT ${ }^{\mathbb{R}}$ cryopreservative (Miles Inc., Elkhart, Ind., U.S.A.) and frozen in isopropyl alcohol cooled with dry ice and stored at $-80^{\circ} \mathrm{C}$ until further processing.

The method of deoxyribonucleic acid (DNA) extraction has been described previously. ${ }^{13)}$ Briefly, frozen sections of $10 \mu \mathrm{m}$ thickness were stained with $\mathrm{HE}$, and the areas of tumor and histologically normal brain were carefully delineated under the microscope. Tumoral and constitutional DNA were extracted from such contiguous sections in each case.

The polymerase chain reaction (PCR) method was used to detect chromosomal polymorphisms employing five microsatellite markers for the long arm of chromosome 22: TOP1P2, D22S300, IL2RB, CYP2D, and D22S274. All primer pairs were pro- 
cured from Research Genetics, Inc. (Huntsville, Ala., U.S.A.) and their sequences can be found in the Genome Data Base (Johns Hopkins University, Baltimore, Md., U.S.A.). The approximate chromosomal localization is shown in Fig. 1, which is compiled from various sex-averaged genetic maps of human chromosome $22 .^{2,3,23)}$ PCR solution $(20 \mu$ l) contained $10 \mathrm{mM}$ Tris-HCl (pH 8.3 at $\left.25^{\circ} \mathrm{C}\right), 50 \mathrm{mM} \mathrm{KCl}, 1.5$ $\mathrm{mM} \quad \mathrm{MgCl}_{2}, \quad 200 \mu \mathrm{M}$ of deoxynucleotide triphosphates, $0.5 \mathrm{U}$ of Taq DNA Polymerase (Takara Shuzo Co., Ltd., Shiga), $0.5 \mu \mathrm{M}$ of each oligonucleotide primer, and $80 \mathrm{ng}$ of each DNA sample. Initial template denaturation at $94^{\circ} \mathrm{C}$ for 3 minutes was followed by 30 cycles at $94^{\circ} \mathrm{C}, 52-55^{\circ} \mathrm{C}$, and $72^{\circ} \mathrm{C}$ for 1,1 , and 2 minutes, respectively, and a final extension step for 5 minutes at $72^{\circ} \mathrm{C}$ (DNA Amplifier MIR-D30; Sanyo Electric Co., Ltd., Osaka).

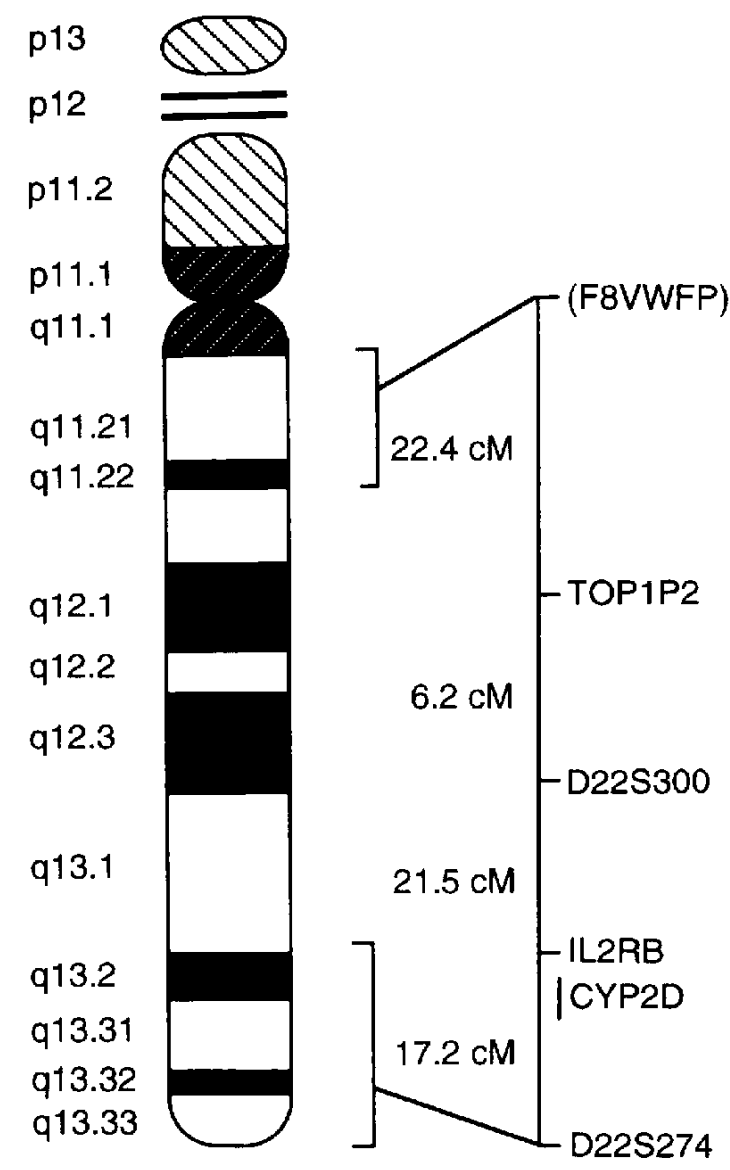

Fig. 1 Sex-averaged genetic map of chromosome 22 showing the chromosomal locations of the microsatellite loci investigated. The approximate interlocus intervals are in centimorgans (cM). The locus within the brackets, F8VWFP, was not analyzed in this study.
DNA extracted from the same sections of tumor or normal brain tissue was used to study the different markers and the PCR analysis was repeated to verify reproducibility of the results.

Ten microliters of each PCR product was analyzed by electrophoresis through a polyacrylamide gel cassette (Multi Gel 15/25; Daiichi Pure Chemicals Co., Ltd., Tokyo) using a constant $40 \mathrm{~mA}$ current for 90 minutes. The resulting bands were stained with 0.5 $\mu \mathrm{g} / \mathrm{ml}$ of ethidium-bromide and finally photographed under ultraviolet transillumination (Spectroline $^{\mathbb{Q}}$, TM-312A; Spectronics, Westbury, N.Y., U.S.A.).

\section{Results}

Fourteen $(74 \%)$ of the 19 samples analyzed showed loss of heterozygosity, that is, one of the two alleles present in the normal brain was absent in the tumor sample (Table 1). Representative cases demonstrating loss of heterozygosity are shown in Fig. 2.

Loss of heterozygosity was observed in $2 / 3(67 \%)$ of astrocytomas, $3 / 5(60 \%)$ of anaplastic astrocytomas, and $9 / 11(82 \%)$ of glioblastomas. The overall mean percentage loss of heterozygosity informative loci, that is the percentage of loci where tumor samples showed loss of heterozygosity of the total loci both alleles in normal brain samples, was $20 \%$ in astrocytomas (range 0-33\%), 33\% in anaplastic astrocytomas (range $0-60 \%$ ), and $40 \%$ in glioblastomas (range $0-75 \%$ ). The frequency of loss of heterozygosity per informative locus was $5 / 16(31 \%)$ in TOP1P2, $8 / 15(53 \%)$ in D22S300, $3 / 13(23 \%)$ in IL2RB, $7 / 18$ (39\%) in CYP2D, and $4 / 14$ (29\%) in D22S274. The locus D22S300 was the most frequently involved and loss of heterozygosity at this locus occurred exclusively in glioblastoma. Furthermore, the various deletions in glioblastoma encompassed the locus D22S300 as the single common region of deletion with eight of the $10(80 \%)$ informative glioblastoma samples demonstrating loss of heterozygosity at D22S300. Two of the other three glioblastomas (Samples 10 and 14) exhibited retention of heterozygosity and the other (Sample 13) was not informative about the D22S300 locus. No such common region of deletion was seen in astrocytomas or anaplastic astrocytomas.

Original and recurrent tumor samples were collected from two patients (Table 1). The original tumors (Samples 3 and 14) showed a single and no loss of heterozygosity, respectively. The corresponding samples from the recurrent tumors (Samples 16 and 15) revealed increased loss of heterozygosity at the D22S300 locus in both tumors and the TOP1P2 locus in one. 
Table 1 Clinical characteristics and loss of heterozygosity

\begin{tabular}{|c|c|c|c|c|c|c|c|c|c|}
\hline \multirow{2}{*}{$\begin{array}{l}\text { Case } \\
\text { No. }\end{array}$} & \multirow{2}{*}{$\begin{array}{l}\text { Histo- } \\
\operatorname{logy}^{*}\end{array}$} & \multirow{2}{*}{$\begin{array}{l}\text { Agel } \\
\text { Sex }\end{array}$} & \multirow{2}{*}{ Tumor location } & \multirow{2}{*}{$\begin{array}{c}\text { Survival** } \\
\text { [months] }\end{array}$} & \multicolumn{5}{|c|}{ Microsatellite loci heterozygosity*** } \\
\hline & & & & & TOP1P2 & $\mathrm{D} 22 \mathrm{~S} 300$ & IL2RB & CYP2D & $\mathrm{D} 22 \mathrm{~S} 274$ \\
\hline 1 & As & $67 / \mathrm{M}$ & frontal & (33) & retain & retain & - & loss & - \\
\hline 2 & As & $39 / \mathrm{F}$ & temporal & (44) & retain & - & - & retain & retain \\
\hline $3^{H}$ & As & $49 / \mathrm{M}$ & frontal & 25 & retain & retain & - & loss & retain \\
\hline 4 & $\mathrm{AA}$ & $42 / \mathrm{F}$ & frontal & (58) & loss & retain & retain & loss & loss \\
\hline 5 & AA & $60 / F$ & frontal & (46) & loss & retain & loss & loss & retain \\
\hline 6 & $\mathrm{AA}(\mathrm{r})$ & $41 / \mathrm{M}$ & frontal & $(46)$ & retain & retain & retain & retain & loss \\
\hline 7 & $\mathrm{AA}(\mathrm{r})$ & $27 / \mathrm{M}$ & pons-parietal & $(47)$ & retain & - & - & retain & retain \\
\hline 8 & $\mathrm{AA}[\mathbf{r}]$ & $46 / F$ & frontal & 22 & retain & - & retain & retain & - \\
\hline 9 & GB & $69 / F$ & parietal & 6 & loss & loss & - & retain & - \\
\hline 10 & GB & $50 / \mathrm{M}$ & temporal & 17 & retain & retain & loss & loss & retain \\
\hline 11 & GB & $64 / \mathrm{M}$ & occipital & 7 & - & loss & retain & - & - \\
\hline 12 & GB & $9 / \mathrm{M}$ & pons-parietal & 9 & - & loss & retain & loss & retain \\
\hline 13 & GB & $50 / F$ & temporo-occipital & 5 & - & - & retain & retain & retain \\
\hline $14^{\text {Hth }}$ & GB & $53 / \mathrm{M}$ & temporo-parietal & 25 & retain & retain & retain & retain & retain \\
\hline $15^{\# \#}$ & $\mathrm{~GB}(\mathrm{r})$ & $54 / \mathrm{M}$ & temporal & 14 & retain & add. & retain & retain & retain \\
\hline $16^{4}$ & $\mathrm{~GB}(\mathrm{r})$ & $50 / \mathrm{M}$ & frontal & 15 & add. & add. & - & loss & retain \\
\hline 17 & GB(r) & $39 / \mathrm{M}$ & temporal & 25 & loss & loss & loss & retain & - \\
\hline 18 & $\mathrm{~GB}(\mathrm{r})$ & $47 / M$ & frontal & 35 & retain & loss & retain & retain & loss \\
\hline 19 & GB(r) & $42 / F$ & cerebellar & 12 & retain & loss & retain & retain & loss \\
\hline
\end{tabular}

*World Health Organization classification. ${ }^{11}$ AA: anaplastic astrocytoma, As: astrocytoma, GB: glioblastoma, r: recurrent tumor. ${ }^{* *}$ Figures in brackets indicate the patient was alive. *** retain: retention of heterozygosity, loss: loss of heterozygosity, add.: additional loss of heterozygosity during tumor progression or recurrence, —: non-informative. \#.\#Pairs of original and recurrent tumors.

There was no apparent relationship between the frequency of loss of heterozygosity and patient survival following diagnosis. However, patients with glioblastoma showing retention of heterozygosity at the TOP1P2 and/or D22S300 loci (Samples 10, 14, 15, 18 , and 19) survived longer than those without such retention (Samples 9, 11, 12, 16, and 17); with mean survival times of $20.6 \pm 9.4$ (SD) versus $12.4 \pm 7.9$ (SD) months, although this was not statistically significant.

\section{Discussion}

Loss of heterozygosity affecting chromosome 22q occurred in 14 of the $19(74 \%)$ astrocytic tumors in the present study. The previously reported overall loss of heterozygosity has been $10-30 \%,{ }^{9,18,20)}$ although $44 \%$ in female patients. ${ }^{6)}$ Our use of microsatellite markers rather than restriction fragment length polymorphisms hinders direct comparisons, but the difference is most likely due to the informativeness and chromosomal localization of the markers or probes employed, as well as variations in the pathological classification of the tumors analyzed. Additionally, our meticulous efforts to separate tumor from surrounding brain tissue may have resulted in successful avoidance of contamination by normal tissue and so reduced false-negative findings. However, the observed deletion patterns are different from those of previous reports, in which the terminal deletion or total loss of the long arm was more frequently observed. The deletion patterns in the present study may be a consequence of the occurrence of microsatellite instability. ${ }^{19)}$

The frequency of loss of heterozygosity in various histological grades was $67 \%$ in astrocytomas, $60 \%$ in anaplastic astrocytomas, and $82 \%$ in glioblastomas. Apparently there is no significant correlation between the presence of chromosome 22 deletion and the malignancy grade of the tumor, but the numbers of astrocytomas and anaplastic astrocytomas in the present study were too small to draw any inference. Nevertheless, the incidence of similar frequencies of $22 q$ deletions in the three grades of tumor substantiates previous reports that loss of genetic information from this chromosome may be an early event in the genesis of glioma. ${ }^{4,16)}$

The loss of chromosomal alleles is thought to indicate the possible localization and involvement of the tumor suppressor gene. However, the precise location of the putative glioma suppressor gene(s) on chromosome 22 remains ambiguous. Previous 

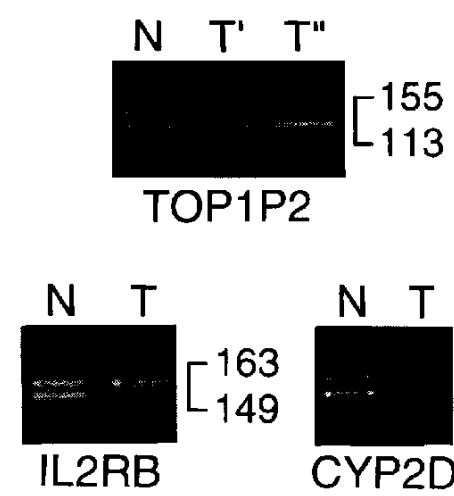
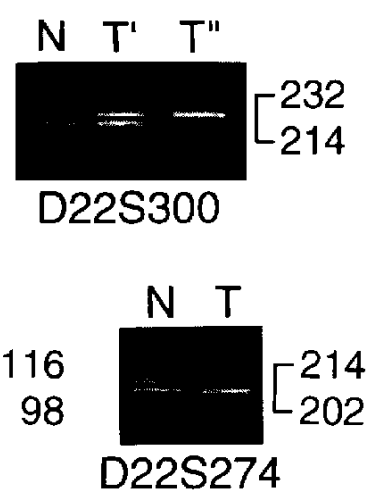

Fig. 2 Examples of loss of heterozygosity: Absence of one of the alleles in tumoral deoxyribonucleic acid (DNA) and presence of both alleles in normal brain DNA (N). Samples 17, 10, and 19 (lower row, left to right) show loss of heterozygosity at IL.2RB, CYP2D, and D22S274 loci, respectively. Additional loss of heterozygosity during tumor progression or recurrence is seen in original $\left(T^{\prime}\right)$ and recurrent tumor $\left(T^{\prime \prime}\right)$ samples collected from the same patients. Samples 3 and 16 (upper left) show retention of heterozygosity and loss of heterozygosity at the TOP1P2 locus, respectively, and Samples 14 and 15 (upper right) show similar findings at the D22S300 locus. The figures on right side denote approximate band size in base pairs (marker 9, $\phi$ X174/HinfI digest; Nippon Gene Corp., Tokyo).

cytogenetic and loss of heterozygosity studies have suggested that the chromosome 22 segment commonly involved in gliomas includes 22q11-q13. Aberrations of $q 11-q 13.1$ were seen in 13/17 gliomas presenting with such loss of heterozygosity, ${ }^{97}$ aberrations of q12.3-q13.1 in all three cases, ${ }^{10]}$ and aberrations of $\mathrm{q} 13$ in all three cases, ${ }^{17)}$ in $4 / 6$ cases, ${ }^{16)}$ and in five cases. ${ }^{20)}$ In our study, the various deletions observed in glioblastoma narrowed the above region down to q12.1-q13.1 with eight of the $10(80 \%)$ informative cases showing loss of heterozygosity at this locus (D22S300). The implication of D22S300 locus in the genesis of brain tumors is still unclear, but a recent investigation demonstrated loss of heterozygosity at D22S300 in nine of $11(82 \%)$ informative cases of meningiomas. ${ }^{\text {s) }}$

The chromosomal segments that undergo cumulative genetic alterations during tumor progression in astrocytic tumors have only recently been identified with reports of putative loci on chromosomes $10 \mathrm{q}^{21)}$ and 19q. ${ }^{24 l}$ We observed increased loss of heterozygosity in two patients in whom both the original and recurrent tumor samples were analyzed. Interes- tingly, the D22S300 locus (22q12.1-q13.1) was involved in both and the TOP1P2 (q11.2-q13.1) in one. Furthermore, the original tumor (Sample 14) with no aberrations on chromosome 22, possibly due to involvement of other chromosomes, recurred after 11 months and developed loss of heterozygosity at the D22S300 locus (Sample 15). Since loss of heterozygosity at the D22S300 locus was frequently observed in other glioblastomas but not in astrocytomas or anaplastic astrocytomas, these glioblastomas may have acquired this genetic change during tumor progression. The chromosomal region 22q12-q13 includes several genes with known functions including NF2, ${ }^{22)}$ and members of the S-lac lectin gene family (LGALS1 and LGALS2, which encodes soluble galactoside-binding lectin). ${ }^{14)}$ Although chromosome 22 deletions in astrocytic tumors most frequently occurs in the NF2 region (22q12), the NF2 gene is not altered in these tumors. ${ }^{5,9)}$ The S-lac lectins may act as cell growth inhibitors in a similar way to the interferons, ${ }^{26)}$ and are possibly implicated in metastasis and neoplasia. ${ }^{15]}$

Histological or immunological markers are useful to assess the prognosis of astrocytic tumors in general, but there is considerable variation in the response to therapy and postoperative survival. Various schemes of genetic subdivision in gliomas for the purpose of prognosis have been proposed. ${ }^{7,25)}$ The influence of chromosome 22 aberrations has not yet been addressed, but allele losses of chromosome 22 are not associated with worse prognosis in gliomas. ${ }^{6)}$ We could not find any obvious correlation between the presence or absence of loss of heterozygosity on chromosome 22 and the postoperative survival in our patients.

The present study suggests that loss of heterozygosity in the q12.1-q13.1 segment of chromosome 22 around the D22S300 microsatellite locus may be involved in the pathogenesis of glioblastomas. Further analysis of the 22q12.1-q13.1 region in a larger series may be helpful in understanding the biology of astrocytic tumors.

\section{Acknowledgments}

This investigation was supported in part by the Grant-in-Aid for Cancer Research (4-23) from the Japanese Ministry of Health and Welfare, and Grantin-Aid for Scientific Research (07671514) from the Japanese Ministry of Education, Science and Culture.

\section{References}

1) Akagi $K$, Kurahashi $H$, Arita $N$, Hayakawa $T$, 
Monden M, Mori T, Takai S, Nishisho I: Deletion mapping of the long arm of chromosome 22 in human meningiomas. Int J Cancer 60: 178-182, 1995

2) Bentley DR, Dunham I: Mapping human chromosomes. Curr Opin Genet Dev 5: 328-334, 1995

3) Buetow KH, Duggan D, Yang B, Ludwigsen S, Puck J, Porter J, Budarf M, Spielman R, Emanuel BS: A microsatellite-based multipoint index map of human chromosome 22. Genomics 18: 329-339, 1993

4) Collins VP, James CD: Gene and chromosomal alterations associated with the development of human gliomas. FASEB J 7: 926-930, 1993

5) De Vitis LR, Tedde A, Vitelli F, Ammannati F, Mennonna P, Bono P, Grammatico B, Grammatico P, Radice P, Bigozzi U, Montali E, Papi L: Analysis of the neurofibromatosis type 2 gene in different human tumors of neuroectodermal origin. Hum Genet 97: 638-641, 1996

6) Diedrich U, Lucius J, Bittermann H-J, Schlosser M, Eckert B, Behnke J, Pabst B: Lass of alleles in brain tumours: Distribution and correlations with clinical course. J Neurol 242: 707-711, 1995

7) Ganju V, Jenkins RB, O'Fallon JR, Scheithauer BW, Ransom DT, Katzmann JA, Kimmel DW: Prognostic factors in gliomas. Cancer 74: 920-927, 1994

8) Harada $T$, Irving RM, Xuereb JH, Barton DE, Hardy DG, Moffat DA, Maher ER: Molecular genetic investigation of the neurofibromatosis type 2 tumor suppressor gene in sporadic meningioma. J Neurosurg 84: $847-851,1996$

9) Hoang-Xuan K, Merel P, Vega F, Hugot J-P, Cornu P, Delattre J-Y, Poisson M, Thomas G, Delattre O: Analysis of the NF2 tumor-suppressor gene and of chromosome 22 deletions in gliomas. Int $J$ Cancer 60: 478481, 1995

10) James CD, He J, Carlbom E, Mikkelsen T, Ridderheim P-A, Cavenee WK, Collins VP: Loss of genetic information in central nervous system tumors common to children and young adults. Genes Chromosomes Cancer 2: 94-102, 1990

11) Kleihues P, Burger PC, Scheithauer BW: The new WHO classification of brain tumours. Brain Pathol 3: 255-268, 1993

12) Louis DN, Ramesh V, Gusella JF; Neuropathology and molecular genetics of neurofibromatosis 2 and related tumors. Brain Pathol 5: 163-172, 1995

13) Maruno $M$, Yoshimine $T$, Muhammad AKMG, Tokiyoshi K, Hayakawa T: Loss of heterozygosity of microsatellite loci on chromosome $9 p$ in astrocytic tumors and its prognostic implications. J Neurooncol 30: 19-24, 1996

14) Mehrabian M, Gitt MA, Sparkes RS, Leffler H, Barondes SH, Lusis AJ: Two members of the S-lac lectin gene family, LGALS1 and LGALS2, reside in close proximity on human chromosome 22q12-13. Genomics 15: 418-420, 1993

15) Raz A, Pazerini G, Carmi P: Identification of a metastasis-associated, galactoside-binding lectin as a chimeric gene product with homology to an IgE-binding protein. Cancer Res 49: 3489-3493, 1989
16) Rey JA, Bello MJ, de Campos JM, Vaquero J, Kusak ME, Sarasa JL, Pestana A: Abnormalities of chromosome 22 in human brain tumors determined by combined cytogenetic and molecular genetic approaches. Cancer Genet Cytogenet 66: 1-10, 1993

17) Rey IA, Bello MJ, Jimenez-Lara AM, Vaquero J, Kusak ME, de Campos JM, Sarasa JL, Pestana A: Loss of heterozygosity for distal markers on $22 \mathrm{q}$ in human gliomas. Int J Cancer 51: 703-706, 1992

18) Seizinger $B R$, Klinger HP, Junien $C$, Nakamura $Y$, Beau ML, Cavenee W, Emanuel B, Ponder B, Naylor S, Mitelman F, Louis D, Menon A, Newsham I, Decker J, Kaelbling M, Henry I, von Deimling A: Report of the committee on chromosome and gene loss in human neoplasia. Cytogenet Cell Genet 58: 10801096, 1991

19) Thibodeau SN, Bren G, Schaid D: Microsatellite instability in cancer of the proximal colon. Science 260: 816-819, 1993

20) Thiel G, Losanowa T, Kintzel D, Nisch G, Martin H, Vorpahl K, Witkoski R; Karyotypes in 90 human gliomas. Cancer Genet Cytogenet 58: 109-120, 1992

21) Tokiyoshi K, Yoshimine T, Maruno M, Muhammad AKMG, Hayakawa T: Accumulation of allelic losses of chromosome 10 in human gliomas at recurrence. Clin Mol Pathol 49: M218-M222, 1996

22) Trofatter JA, MacCollin MM, Rutter JL, Murrell JR, Duyao MP, Parry DM, Eldridge R, Kley N, Menon AG, Pulaski K, Haase VH, Ambrose CM, Munroe D, Bove C, Haines JL, Martuza RL, MacDonald ME, Seizinger BR, Short MP, Buckler AJ, Gusella JF: A novel moesin-, ezrin-, radixin-like gene is a candidate for the neurofibromatosis 2 tumor suppressor. Cell 72: 791-800, 1993

23) Vallada HP, Collins JE, Dunham I, Dawson E, Murray RM, Gill M, Collier DA: Genetic mapping of 14 short tandem repeat polymorphisms on human chromosome 22. Hum Genet 93: 688-690, 1994

24) von Deimling A, Bender B, Jahnke R, Waha A, Kraus I, Albrecht S, Wellenreuther R, Fassbbender F, Nagel J, Menon AG, Louis DN, Lenartz D, Schramm J, Wiestler OD: Loci associated with malignant progression in astrocytomas: A candidate on chromosome 19q. Cancer Res 54: 1397-1401, 1994

25) von Deimling $A$, von Ammon $K$, Schoenfeld $D$, Wiestler OD, Seizinger BR, Louis DN: Subsets of glioblastoma multiforme defined by molecular genetic analysis. Brain Pathol 3: 19-26, 1993

26) Wells V, Mallucci L: Identification of an autocrine negative growth factor: Mouse $\beta$-galactoside-binding protein is a cytostatic factor and cell growth regulator. Cell 64: 91-97, 1991

Address reprint requests to: T. Yoshimine, M.D., Department of Neurosurgery, Osaka University Medical School, 2-2 Yamadaoka, Suita, Osaka 565, Japan. 


\section{Commentary}

In the present study, the authors analyzed the deletion of chromosome 22 in 19 astrocytic tumors using five microsatellite markers. The authors found that the loss of heterozygosity was frequently observed in the region between the centromere and q13.1 of chromosome 22. The percentage of the loss of heterozygosity $(74 \%)$ was high, suggesting that this region contains a tumor suppressor gene. However, these losses do not appear to correlate with the malignancy grade of astrocytoma.

Chromosomal alteration in glioma has been studied by many laboratories and the focuses of the studies have been on chromosomes 10, 17, 7p, and 9p. RecentIy, a gene on chromosome 10, termed PTEN, was cloned as a candidate for the tumor suppressor gene for glioblastoma. A tumor suppressor gene, NF2, is located on chromosome 22, and mutation in NF2 was previously analyzed by others. However, as the author mentioned, mutation in NF2 was rarely detected in astrocytic tumors, indicating that NF2 is not involved in the occurrence of astrocytoma.

It is interesting that there is no significant correlation between the presence of chromosome 22 deletion and the malignancy grade of the tumor. The total number analyzed in the present study was too small and the distance between each microsatellite was too far. To determine the importance of this alteration, I hope the authors perform a high density search of this area with a larger number of patients.

Jun-ichi KURATSU, M.D.

Department of Neurosurgery

Kumamoto University School of Medicine Kumamoto, Japan

This manuscript by Muhammad and colleagues demonstrates the common loss of genetic material on chromosome 22 in astrocytic tumors including glioblastoma. This work adds to other work in the literature and suggests that the locus defined by the authors on chromosome 22 may, in addition to genes at other loci, be responsible for the initiation and/or progression of these tumors. Future steps will likely include the identification of the gene (or genes) in the chromosome 22q12.0-q13.1 segment responsible for tumorigenesis, the function of the gene product, and its relationship to other genes shown to be involved in the development of related tumors. The authors are to be complimented for this addition to our understanding of astrocytoma development.

Robert L. MARTUZA, M.D. Department of Neurosurgery
Georgetown University Medical Center Washington, D.C., U.S.A.

In this study, the authors have analyzed regions of deletions on chromosome 22q in patients with astrocytic neoplasms. These results were compared to matched normal brain tissues. They found that a locus at 22q12.1-q13.1 was most frequently involved. Interestingly, there was no difference in loss of heterozygosity between astrocytomas, anaplastic astrocytomas, and glioblastoma multiforme, suggesting that loss of alleles on chromosome 22q may be an early event in the pathogenesis of astrocytomas. Although the NF-2 gene is nearby, there are conflicting data as to whether this gene is truly altered in human astrocytomas. With the recent finding of a novel tumor suppressor gene on chromosome 10 (PTEN), this work by Muhammad et al. sets the stage for a definitive search for additional tumor suppressors on chromosome 22.

\section{James T. RUTKA, M.D., F.R.C.S.C. Division of Neurosurgery The Hospital for Sick Children Brain Tumor Research Laboratory University of Toronto Ontario, Canada}

The authors demonstrated a higher incidence of loss of heterozygosity affecting chromosome $22 q$ in astrocytic tumors compared with previous reports, with similar incidences in astrocytomas (67\%), anaplastic astrocytomas $(60 \%)$, and glioblastomas $(82 \%)$, and found no significant correlation between the presence of chromosome 22 deletion and the malignancy grade of the astrocytic tumors. They also described that loss of heterozygosity at the D22S300 locus was frequently $(80 \%)$ observed in glioblastomas but not in astrocytomas or anaplastic astrocytomas and that some glioblastomas may acquire genetic changes or develop loss of heterozygosity at the D22S300 locus during tumor progression.

These findings seem to be very interesting in respect to the pathogenesis of glioblastomas or progression of astrocytic tumors. However, the number of the tumors analyzed in this study was very small and further analysis is required to understand the pathogenesis of the tumors and correlation between the genetic abnormalities and patients' survival.

Ryuichi TANAKA, M.D. Department of Neurosurgery Brain Research Institute Niigata University Niigata, Japan 